\title{
Integrating Health Promotion Into Nursing Curricula in Hong Kong
}

\author{
Marie Tarrant, RN, MN, and Sophia Siu-Chee Chan, RN, RSCN, \\ PRDHCE (Nursing), MEd, PhD \\ Department of Nursing Studies \\ University of Hong Kong
}

\begin{abstract}
The health care system in Hong Kong has historically been steeped in the biomedical paradigm. Health care reform, however, is finally putting health promotion on the agenda of governments and health care providers. As the largest group of providers in Hong Kong, nurses must assume a leadership role in the transition of the current illness-focused system to one that emphasizes health and promotes wellness. For nurses to take up the challenge of health promotion, they need to acquire the requisite knowledge and skills. Nursing curricula must emphasize this new paradigm and provide opportunities for students to develop expertise in health promotion and disease prevention. This article describes a health-promotion initiative carried out by 1st-year students in an undergraduate nursing program in Hong Kong. The health-promotion project aims to prepare graduates who will be able to meet health care needs and function effectively in the future health care system. Not only will these nurses be capable of becoming future leaders of the health-promotion movement in Hong Kong, they are also contributing to the health and wellness of Hong Kong citizens.
\end{abstract}

Historically, nursing practice in Hong Kong has been disease oriented, and hospital-base d training has been the primary method of educating nurses. Invariably, the focus of these programs was skill acquisition with little emphasis on critical thinking, decision-making skills, or self-directed learning (Hospital Authority, 1992). Despite the proliferation of university-base d nursing education programs worldwide since the 1950s, it was only in 1990 that the Hong Kong Government gave approval for universities to initiate nursing degree programs (Chan \& Wong, 1999). Consequently, few nurses in Hong Kong are prepared for, or would recognize, their key role in health promotion and disease prevention.

Increasingly, nurses need health-promotion skills as the disease patterns in Hong Kong have completed the epidemiological transition from communicable to chronic diseases (Galbally, Hsu-Hage, \& Borthwick, 1999). Preventable chronic diseases, such as

Requests for reprints should be sent to Marie Tarrant, Department of Nursing Studies, University of Hong Kong, 4/F, Academic and Administrative Block, Faculty of Medicine, 21 Sassoon Road, Hong Kong. E-mail: tarrantm@hkucc.hku.hk 
cancer, heart disease, and cerebrovascular disease now account for over one half (59\%) of all deaths in Hong Kong (The Government of the Hong Kong SAR, 1999). In addition, proposed changes to the health care system in Hong Kong will necessitate an increasing number of nurses with skills and knowledge in health promotion and disease prevention. The government-commissione d "Harvard Report" concluded that the Hong Kong health care system overemphasize s hospital-base d curative care and, in its present form, is outdated and unsustainable (The Harvard Team, 1999). Major restructuring of the system is required with a greater focus on prevention and health promotion.

Since the initiation of nursing degree programs in Hong Kong, the aim of local universities has been to expand the emphasis of nursing from the current illness paradigm to also include the health paradigm. If nurses are to take up the challenge of integrating health-promotion concepts into nursing practice, undergraduate programs need to incorporate specific opportunitie s dedicated to learning health-promotion skills into the curriculum (Hills \& Lindsey, 1994; Pender, Barkauskas, Hayman, Rice, \& Anderson, 1992). A greater role for nurses in health promotion and disease prevention means that student learning experiences must shift toward more community-based practice setting s that emphasize experiential methods and involve the students actively in the learning process (Oermann, 1994a, 1994b). In line with worldwide trends and the impending changes in Hong Kong, health promotion is a major focus of teaching in the Bachelor of Nursing Program at the University of Hong Kong. This article reviews a Health Promotion Project (HPP) implemented in the 1st year of the Bachelor of Nursing Program. The HPP was designed to prepare graduates for the changing role of the nurse and to be the leaders of this change in Hong Kong.

\section{OVERVIEW}

The University of Hong Kong offers a 4-year Bachelor of Nursing undergraduate degree program. The 1st year of the program focuses on the healthy adult. In this 1st year, nursing courses concentrate on the nursing process, communication skills, health assessment, and health promotion. Two clinical practica offer students opportunitie s to assess and interact with individual s and groups in various community-based settings. The HPP is introduced to students in the second semester of the 1st year as part of a 13-week, health-promotion course. The focus of the HPP is the young adult, 16 to 25 years of age, and the aim is to provide students with the experience of planning, implementing, and evaluating a health-promotion intervention for a selected young adult group. The goals and objectives of the HPP are outlined in Table 1.

One of the major goals for the curriculum in this 1st year is to give the students a good understanding of the nursing process. Therefore, the nursing process is used as the framework to plan the HPP as presented in Table 2. Students form into groups of eight or nine, and the first task is to conduct a literature review of the common health problems of young adults in Hong Kong. The information gathered from the literature review pro- 
TABLE 1

Goals and Objectives for the Health Promotion Project

Goals

To introduce and strengthen the concepts of health promotion to students at an early stage in the curriculum.

To provide students with the experiences of planning and conducting health-promotion interventions.

To promote the health of young adults in the community.

Objectives

To identify the health-related problems of young adults in the Hong Kong community.

To assess the health needs of the selected target group.

To identify factors (physical, psychological, social, cultural, and environmental) contributing to the health of young adults.

To identify factors (physical, psychological, social, cultural, and environmental) impeding the health of young adults.

To develop and implement health-promotion intervention(s) that can meet the health needs of the selected target group.

To evaluate the effectiveness of the implemented health-promotion intervention(s).

To utilize effective communication skills through the process of assessment, planning, implementation, and evaluation.

To utilize different resources in developing the appropriate health-promotion strategies.

To develop the ability and insight in analyzing contemporary health issues related to young adults in Hong Kong.

TABLE 2

Project Planning Guide

\section{Assessment}

Target group characteristics

Health needs

Physical factors

Psychological factors

Social factors

Cultural factors

Environment factors

Community resources

Health-problem identification

Planning

Gain consent of target group

Set goals and objectives for the health-promotion intervention(s)

Develop a plan for the health-promotion intervention(s)

Note feasibility of project

Work out proposal for project

Implementation

Action! Carry out the health-promotion intervention(s) for the selected target group.

Evaluation

Structure

Process

Outcome

vides students with a thorough overview of the range and scope of health problems frequently encountered by young adults. These identified health problems are outlined in Table 3. Next, students select a target group with which to conduct the HPP. Students then assess the health needs of the selected group and plan and implement appropriate 
TABLE 3

Common Health Problems in Young Adults in Hong Kong

Stress

Suicide

Smoking

Eating disorders

Obesity

Sedentary lifestyles

Sexually transmitted diseases

Unplanned pregnancy

health-promotion interventions aimed at improving health and promoting wellness. Finally, students evaluate the effectiveness of the interventions.

The health-promotion intervention s can be initiated in any environment or with any group of young adults that welcomes the students and is willing to participate. Previous interventions by students have been undertaken in secondary schools, universities, workplaces, community centers, and correctional facilities. Although the students are not restricted to specific methods of health promotion, the majority choose to implement

TABLE 4

Past Health Promotion Projects Completed by Students

\begin{tabular}{lc} 
Project Title & Target Group/Agency \\
\hline $\begin{array}{l}\text { Sports injury prevention } \\
\text { and treatment }\end{array}$ & $\begin{array}{c}\text { School athletes in a secondary } \\
\text { school in Hong Kong }\end{array}$
\end{tabular}

Preventing repetitive strain injuries in computer users

Smoking and health

Headache, insomnia, and back pain

Low back pain
Local university students who used a computer for more than $4 \mathrm{hr}$ per day

Correctional institution for young offenders

New migrant women from mainland China in a community center

Filipino domestic helpers who gathered in the park on Sunday
Description of Interventions

Health information session and pamphlet produced demonstrating appropriate use of athletic protective devices. Interactive session demonstrating use of protective devices and immediate treatment of sports injuries.

Production of video compact disc demonstrating ergonomic methods of using computers. The compact disc was distributed to the target group and pretest and posttest design was used to evaluate the outcome.

Interactive teaching methods such as simulations, a matching game, talks, and small group discussions. Pretest and posttest design was used to evaluate the outcome.

Health education materials were posted on display boards and health education materials and pamphlets were distributed to participants.

A health talk and a demonstration of the correct posture in handling domestic work was organized. An interactive question and answer session was held. 
health-education programs on topics relevant to the target group. Topics for the HPP, however, are selected only after the students have assessed the health needs and solicited the expressed health concerns of the target group. Topics covered in the past have included nutrition and eating disorders, sexually transmitted diseases and unplanned pregnancies, tobacco and health, drug and alcohol awareness, sports injuries, computer-related health problems, and stress reduction and suicide prevention. Some examples of previous projects conducted by students are highlighted in Table 4 .

\section{Preparation of Students}

The HPP is one component in a course on health promotion. Prior course s have introduced the students to the nursing process and basic communication skills. Along with the HPP, the health-promotion course simultaneously engages the students in small-group, problem-based learning tutorials that provide the theoretical foundations for implementing the HPP. During the same semester, students are also involve din a 9-week community health nursing practicum in which they observe and participate in health promotion and health-education programs for clients across the life span. These clinical encounters provide students with the opportunity to practice and refine their health-promotion skills before the implementation of their own health-promotion interventions.

\section{Role of Faculty}

Students are closely supervised throughout the duration of the project. For 1st-year students, the HPP can be a daunting task. Therefore, faculty members meet with each group once weekly to review their progress, provide guidance, and discuss any issues that arise. More frequent meetings can be arranged if required. At each point in the project, faculty approval must be gained before students can proceed. Faculty members also act as resource people to help students access appropriate people, information, and materials.

\section{DESCRIPTION OF THE HEALTH-PROMOTION PROJECT}

\section{Assessment}

Based on the data collected during the literature review of the common health problems in young adults, students develop and administer an assessment tool to assess the health problems or needs of the target group or both. To conduct the assessment, students approach the selected target group or agency (e.g., the school principal if the target group is senior high school students). In most cases, students call the agency involved and follow up with a letter explaining the HPP, detailing what they plan to do, and requesting access 
to the selected group. Students also examine the characteristics and composition of the target group and identify physical, psychological, social, cultural, and environmental factors that influence their health. On completion of the assessment, students analyze all of the data to identify and prioritize actual or potential health problems. To determine the focus of their HPP, students consider the following questions (McKenzie \& Smeltzer, 1997):

1. What is the most pressing health problem?

2. Are there sufficient resources to address the problem?

3. Can the problem be best addressed by a health-promotion intervention?

4. Is the allocated time sufficient to address the health problems?

5. Does the target group perceive the identified health problems as important?

\section{Planning}

To begin the planning process, the groups gather information about the identified health problem or problems. This is done by accessing materials pertaining to the selected topic such as the current literature, books, web sites, and so forth. Students also approach the local Department of Health and various community agencies to gather information and to locate resources such as pamphlets, display boards, and videos that can be used in the health-promotion sessions.

Students must submit a detailed proposal of their intended HPP by Week 4 of the semester. The proposal outlines the implementation of the project, goals and objectives, health-promotion strategies they plan to use, and methods of evaluation. At this point, faculty review the stated goals and objectives with the group. To plan, implement, and evaluate an effective health-promotion program, the students need to clearly articulate the expected outcomes. Constructing simple and concise goals and measurable and specific objectives are the most important tasks (McKenzie \& Smeltzer, 1997). The objectives outlined by the groups provide the foundation for their eventual evaluation of the HPP. Accordingly, the HPP proposals must also include the group's evaluation criteria and how they plan to evaluate their project. Faculty review the proposals to ensure that the projects the students have chosen are realistic and practical while addressing the genuine health needs of the target group. In addition, the selected health-promotion strategies are reviewed to ensure that they are appropriate to both the age and educational level of the audience (Clark, 1999).

\section{Implementation}

The HPP can be implemented at any point after Week 4, and it must be completed before the end of the semester. Because of time constraints, students' heavy workloads, and the amount of preparation involved, students usually carry out the implementation from 
Week 8 to Week 13 of the semester. The implementation is often anxiety producing. For most students this is their first experience functioning in the role of a nurse with a large group of people. Hence, they are concerned with appearing both knowledgeable and professional. The groups do a lot of preparation for the sessions as they want to be able to answer participants' questions accurately and completely. During the implementation, students also learn that in the "real world" even the most meticulou s planning cannot account for all of the variables encountered. Students learn to cope with unexpected occurrences such as malfunctioning equipment, inadequate or inappropriate venues, last minute changes or cancellation sy the agency, adverse weather, and any unusual behavior of the target group.

\section{Evaluation}

"There are two reasons to evaluate a program: to improve it or to determine its effectiveness" (McKenzie \& Smeltzer, 1997, p. 225).

To generate meaningful evaluation data, the evaluation must be considered early in the planning process (McKenzie \& Smeltzer, 1997). Students begin planning the evaluation when they develop their goals and objectives. Students evaluate the project according to three criteria: structure, process, and outcome. The first step in evaluation is examining the structural elements that impacted the implementation of the project. Factors such as the environment, agency staff, venue for implementation, and equipment are considered. Although these factors are not usually under the control of the students, they do impact the outcome of the project. Consequently, students learn how to maximize available resources and to explore new resources when necessary.

Students ask participants to evaluate the process and how well the HPP was implemented. The purpose of process evaluation is to gather information during program implementation so that adjustments and improvements can be made to the program (McKenzie \& Smeltzer, 1997). When negative feedback is received from the participants, students often perceive this as a failure on their part. Furthermore, students conduct self-evaluation by reflecting on their own performance in the planning and implementation of the project. Inevitably, they discover that there is some room for improvement. These situation s provide excellent learning opportunitie s to demonstrate the value of feedback and evaluation data in the cycle of ongoing assessment and improvement. Students learn that partially met objectives provide a starting point for follow-up and should not be considered a failure (Allender \& Spradley, 2001).

Overall, evaluation data collected by the students show that the health-promotion projects are well received. Participants developed an increased awareness of health issues and health knowledge and had a greater appreciation for health promotion and disease prevention after the projects. Several agencies have invited the students back to imple- 
ment their projects with other groups. As one of the objectives of the HPP is to improve the health of young adults in Hong Kong, it is rewarding for both students and faculty to see the valuable contribution that the students make.

Finally, outcomes of the project are evaluated. Some groups choose the pretest-posttest design based on the objectives set during the planning stage. Other groups request that participants self-rate their increase in knowledge and awareness of the selected topics. To evaluate outcomes, groups must answer the following two questions: (a) Did the program achieve the effect that was intended, and (b) did any good result from the program (Pirie, 1999)? Unfortunately, it is usually not possible for the students to conduct long-term evaluation to measure the lasting impact of their projects. However, the importance of ongoing evaluation in health promotion is discussed and strategies for long-term follow-up are highlighted.

\section{ASSESSMENT OF STUDENTS}

Evaluation s of student performance on the HPP is achieved by several methods. At Week 4 , the groups submit their written proposal described earlier in this article. After completion of the project, a day is set aside for all groups to present their project to the other students and faculty. Each student must also submit an individual paper on the HPP. In addition, students complete a peer review form evaluating their own contributions to the project and that of their fellow group members. All four components are assessed and a final letter grade is allocated for the project.

During the project presentations, each group has $30 \mathrm{~min}$ to outline the highlights of its project, including the health problems and needs of the target group, the strategies used to address the health problem, the process of implementing the health-promotion interventions, the outcomes of the project, and their experiences planning and implementing the project. Students and faculty alike enjoy the presentations. Students take pride in presenting their hard work to their colleagues and faculty, and faculty take great pride in the accomplishments of the students and the learning that has taken place. After the presentation, other students and faculty have the opportunity to ask question s and discuss the project. The questions raised by other students are thought provoking and reflect critical thinking. Groups are challenged on such issues as how they conducted their needs assessment, how they determined the health needs of the target group, and why certain interventions were chosen.

\section{Student Reflections on Learning}

In the individual paper students submit on completion of the HPP, they reflect on what they have learned throughout the process of completing the project. With the consent of 
the students, the authors analyzed these reflections to determine if the HPP had achieved the stated goals and objectives. These reflections show that student's learning extended far beyond the expectation s of the faculty. Although the HPP is stressful and demanding, the majority of students wrote that it was a positive and valuable learning experience. Through completion of the HPP, students increased their understanding of the nursing process, learned more about the role of the nurse in health promotion, and were better able to integrate theory into practice. Finally, the HPP improved the students' communication skills and ability to work in groups.

Nursing process. Almost every student responded that the HPP had strengthened their understanding of the nursing process. Using the nursing process gave students an organizational framework for implementing the project and helped them execute the project systematically and methodically. This is especially important as the scope of the project can be overwhelming for 1st-year students. Another benefit of using the nursing process to complete the project is that students can easily understand how it can be applied to any health-promotion intervention, regardless of the topic. This increased their confidence in their ability to carry out other future health-promotion activities.

By organizing a health-promotion program, we had in fact, gone through the nursing process .... The cyclic [sic] process of assessment, planning, implementation, and evaluation was reinforced .... The principle can also be applied to other actual or potential health problems ... such as smoking, alcohol consumption and drug abuse, dieting habits, and stress management.

Role of the nurse. Because the majority of nurses in Hong Kong practice in tertiary care facilities, most students enter the Bachelor of Nursing Program with few expectations for practice outside these acute-care settings. During the 1st year, and especially during the HPP, students express surprise at the broadened scope of nursing practice. In reflecting on their experience, most students noted that they had learned a lot about the role of the nurse in health promotion and health education.

I have a clearer concept of the ... role of nurses in health education. In the past I think what nurses do is the clinical work ... I learned so much in the whole process ... of being a nurse in community health.

Students were also surprised that the participants viewed them as nurses and took them seriously. Nursing students in baccalaureate programs in Hong Kong tend to be young in comparison to other countries and almost all enter directly out of secondary schools. Because of their young age, they often lack confidence in their professional role. The 
HPP increases their self-confidence and enhances the transition from student to autonomous professional.

Theory practice integration. One of the challenges in nursing education is to provide students with opportunities to integrate theory into practice. After completing the HPP, many students express surprise that they are able to apply knowledge learned in the classroom to a practice situation. The concepts about the teaching role of the nurse and health promotion and health-education methods are applied through the implementation of the HPP.

I found that we could fully apply the nursing process to our project. I felt confused when I learned the nursing process. I could not see its importance ... I thought it was only theory .... I had a better understanding of the whole process after finishing the project.

Communication and group skills. For many students this was their first experience working in a group on a major project. Students learned valuable groups skills such as cooperation, teamwork, compromise, conflict resolution, and division of labor. Working in groups of eight or nine was challenging and conflicts naturally occurred. However, groups worked through the problems on their own and faculty were rarely called on to mediate or settle disputes. As a result of working so closely together on the HPP, many students develop friendships within the group that lasted throughout their 4 years in the program.

The HPP also improved many aspects of students' communication skills. After the project, most felt more comfortable in communicating with clients about health topics and more comfortable communicating with a group of clients. They were more aware of the importance of paying attention to clients' education levels and the use of medical terminology and jargon. Students felt that they also became better at communicating with their fellow group members and at expressing their thoughts and ideas. Last, they learned how to communicate with various agencies and institution s and how to deal with the frustrations frequently experienced during such interactions.

\section{CONCLUSIONS}

Current health care reform initiatives in Hong Kong present significant opportunitie s for the nursing profession to lead the paradigm shift from illness to health. As the demand for nurses with the required knowledge and skills increases, nurses with a baccalaureate education will be at the forefront. Taking a leadership role, however, can only be accomplished if undergraduate nursing students are introduced early to the concepts of health 
promotion and disease prevention (Conger, Baldwin, Abegglen, \& Callister, 1999; Sandhu, 1999). Simply teaching health-promotion theory and ideology is insufficient if students are not provided with opportunitie s to develop and practice health-promotion skills (Wass \& Backhouse, 1996). Direct, hands-on health-promotion experiences, such as those described in this article, will enable nurses to make valuable contribution s to the health care system of the future in Hong Kong.

\section{REFERENCES}

Allender, J. A., \& Spradley, B. W. (2001). Community health nursing: Concepts and practice (5th ed.). Philadelphia: Lippincott.

Chan, S., \& Wong, F. (1999). Development of basic nursing education in China and Hong Kong. Journal of Advanced Nursing, 29, 1300-1307.

Clark, M. J. (1999). Nursing in the community (3rd ed.). Stamford, CT: Appleton \& Lange.

Conger, C. O., Baldwin, J. H., Abegglen, J., \& Callister, L. C. (1999). The shifting sands of health care delivery: Curriculum revision and integration of community health nursing. Journal of Nursing Education, 38, 304-311.

Galbally, R., Hsu-Hage, B. H.H., \& Borthwick, C. (1999). Asia and Western Pacific approaches to health promotion: Current opportunities and programs. In N. Bracht (Ed.), Health promotion at the community level: New advances (pp. 175-186). Thousand Oaks, CA: Sage.

The Government of the Hong Kong SAR. (2001). Hong Kong annual report 2000 (Rep. No. F30010100E0). Information Services Department. Retrieved February 1, 2002, from: http://www.info.gov.hk/hk2000/eng/index.htm.

The Harvard Team. (1999). Improving Hong Kong's health care system: Why and for whom? Hong Kong, China: The Government of the Hong Kong SAR.

Hills, M. D., \& Lindsey, E. (1994). Health promotion: A viable curriculum framework for nursing education. Nursing Outlook, 42, 158-162.

Hospital Authority. (1992). Future directions of nursing education: Part I. Basic nursing education for registered nurse. Hong Kong, China: Author.

McKenzie, J. F., \& Smeltzer, J. L. (1997). Planning, implementing, and evaluating health promotion programs: A primer (2nd ed.). Boston: Allyn \& Bacon.

Oermann, M. (1994a). Professional nursing education in the future: Changes and challenges. Journal of Obstetric, Gynecologic, \& Neonatal Nursing, 23, 153-159.

Oermann, M. (1994b). Reforming nursing education for future practice. Journal of Nursing Education, 33, $215-219$.

Pender, N. J., Barkauskas, V. H., Hayman, L., Rice, V. H., \& Anderson, E. T. (1992). Health promotion and disease prevention: Toward excellence in nursing practice and education. Nursing Outlook, 40, 106-112, 120.

Pirie, P. L. (1999). Evaluating community health promotion programs: Basic questions and approaches. In N. Bracht (Ed.), Health promotion at the community level: New advances (pp. 127-134). Thousand Oaks, CA: Sage.

Sandhu, G. K. (1999). Challenges as we enter the new millennium. In C. L. Edelman \& C. L. Mandle (Eds.), Health promotion throughout the lifespan (4th ed., pp. 667-676). St. Louis, MO: Mosby.

Wass, A., \& Backhouse, L. (1996). Preparing students for health promotion: The challenge for Australian nursing in the 90s. Nurse Education Today, 16, 149-154. 